\title{
Pulmonary coagulation and fibrinolysis abnormalities that favor fibrin deposition in the lungs of mouse antibody-mediated transfusion-related acute lung injury
}

\author{
YUNHONG YU*, PENG JIANG*, PAN SUN, NA SU and FANGZHAO LIN \\ Institute of Blood Transfusion, Chinese Academy of Medical Science and Peking Union Medical College, \\ Chengdu, Sichuan 610052, P.R. China
}

Received December 4, 2020; Accepted April 26, 2021

DOI: $10.3892 / \mathrm{mmr} .2021 .12239$

\begin{abstract}
Transfusion-related acute lung injury (TRALI) is a life-threatening disease caused by blood transfusion. However, its pathogenesis is poorly understood and specific therapies are not available. Experimental and clinical studies have indicated that alveolar fibrin deposition serves a pathological role in acute lung injuries. The present study investigated whether pulmonary fibrin deposition occurs in a TRALI mouse model and the possible mechanisms underlying this deposition. The TRALI model was established by priming male Balb/c mice with lipopolysaccharide (LPS) $18 \mathrm{~h}$ prior to injection of an anti-major histocompatibility complex class I (MHC-I) antibody. Untreated mice and mice administered LPS plus isotype antibody served as controls. At $2 \mathrm{~h}$ after TRALI induction, blood and lung tissue were collected. Disease characteristics were assessed based on lung tissue histology, inflammatory responses and alterations in the alveolar-capillary barrier. Immunofluorescence staining was used to detect pulmonary fibrin deposition, platelets and fibrin-platelet interactions. Levels of plasminogen activator inhibitor-1 (PAI-1), thrombin-antithrombin complex (TATc), tissue factor pathway inhibitor (TFPI), coagulation factor activity and fibrin degradation product (FDP) in lung tissue homogenates were measured. Severe lung injury, increased inflammatory responses and a damaged alveolar-capillary barrier in the LPS-primed, anti-MHC-I antibody-administered mice indicated that the TRALI model was successfully established. Fibrin deposition, fibrin-platelet interactions and platelets accumulation in the
\end{abstract}

Correspondence to: Professor Fangzhao Lin, Institute of Blood Transfusion, Chinese Academy of Medical Science and Peking Union Medical College, 26 Huacai Road, Longtan Industry Park, Chenghua, Chengdu, Sichuan 610052, P.R. China

E-mail: fangzhao.lin@ibt.pumc.edu.cn

${ }^{*}$ Contributed equally

Key words: transfusion-related acute lung injury, coagulation, anticoagulation, fibrinolysis, fibrin deposition, fibrin-platelet interaction lungs of mouse models were clearly promoted. Additionally, levels of TATc, coagulation factor V (FV), TFPI and PAI-1 were elevated, whereas FDP level was decreased in TRALI mice. In conclusion, both impaired fibrinolysis and enhanced coagulation, which might be induced by boosted FV activity, increased pulmonary platelets accumulation and enhanced fibrin-platelet interactions and contributed to pulmonary fibrin deposition in TRALI mice. The results provided a therapeutic rationale to target abnormalities in either coagulation or fibrinolysis pathways for antibody-mediated TRALI.

\section{Introduction}

Transfusion-related acute lung injury (TRALI) is an acute respiratory distress syndrome that occurs within $6 \mathrm{~h}$ following blood transfusion and is the main origin of transfusion-associated fatalities (1). The pathophysiological mechanism of TRALI is poorly understood. A 'two-event' pathogenesis model has been suggested (2). Predisposing factors in transfused recipients, including systemic inflammation, shock, surgery and mechanical ventilation, comprise the priming event (1). The second event in TRALI occurs as a result of blood transfusion. Anti-leukocyte antibody or non-antibody factors, such as aged erythrocytes and soluble CD40 ligand that accumulate in stored blood, can activate primed polymorphonuclear leukocytes and further trigger lung injury (3). Previous studies on TRALI have mainly focused on cells, including polymorphonuclear leukocytes, macrophages, platelets, lymphocytes and endothelial cells $(1,4)$. Therefore, its detailed pathophysiology remains to be elucidated. Notably, currently TRALI can only by managed through symptom alleviation via oxygen and mechanical ventilation and no specific therapeutic approaches are available. Elucidating the pathogenesis could aid the development of novel specific therapeutic strategies for TRALI.

The core pathophysiology of acute lung injury (ALI) as well as acute respiratory distress syndrome (ARDS) is the occurrence of fibrin effusion in the lung alveoli $(5,6)$. Fibrin is deposited in the lungs following a wide range of insults to the lungs in both clinical and preclinical models, including severe acute respiratory syndrome coronavirus 2 infection-induced ALI (7), idiopathic pulmonary fibrosis (8), alcohol-induced ALI (9) and trauma-induced ALI (10). Fibrin deposition can 
activate endothelial cells, promote the production and release of proinflammatory mediators and increase vascular permeability, thus aggravating lung injury (11). Fibrin turnover in the lungs originates from enhanced coagulation and impaired fibrinolysis, which may in turn aggravate inflammation by influencing immunomodulation, vascular permeability and chemotaxis (12-15). Therapeutic strategies targeting a reduction in fibrin $(8,16)$, inhibition of coagulation $(17,18)$ and improvement of fibrinolysis (19) hold great potential for lung injury. Vlaar et al (20) reported that both aged erythrocytes and their supernatant worsen lung injury via procoagulant activity and soluble lipids, respectively, both of which are involved in non-antibody-mediated TRALI. However, whether pulmonary fibrin deposition occurs in non-antibody-mediated TRALI is unclear. A case-control study showed that restrictive transfusion of erythrocytes or multiple transfusions can lead to TRALI and systemic imbalances in coagulation (21). The role of fibrin turnover in the pathogenesis of antibody-mediated TRALI, which accounts for $\sim 80 \%$ of cases, is poorly understood. Knowledge of the pulmonary abnormalities that favor fibrin deposition is critical to explore the pathophysiology of antibody-mediated TRALI.

The present study explored fibrin turnover in a mouse model of TRALI established using liposaccharide (LPS) priming followed by an anti-major histocompatibility complex class I (MHC-I) antibody challenge. It demonstrated that multiple local abnormalities contributed to fibrin deposition in the lungs. Therefore, therapies aimed at the prevention of pulmonary fibrin deposition or turnover of fibrin in TRALI might be a potential approach to improving survival.

\section{Materials and methods}

Reagents. Antibodies for injection into mice, namely, anti-mouse $\mathrm{H}-2 \mathrm{Kd}$ and $\mathrm{H}-2 \mathrm{Dd}$ IgG2a MHC-I molecules (cat. no. BE0180; clone 34-1-2S) and mouse isotype control IgG2a (cat. no. BE0085; clone C1.18.4), were obtained from Bio X Cell. For fibrin immunofluorescence staining, rabbit polyclonal anti-fibrinogen was purchased from Abcam (cat. no. ab34269). A CD41a monoclonal antibody for immunofluorescence detection of CD41 was purchased from Invitrogen (cat. no. 2072475; Thermo Fisher Scientific, Inc.). LPS (Escherichia coli 0111: B4) was obtained from Sigma-Aldrich (Merck KGaA). Bovine serum (cat. no. 22012-8612) was purchased from Zhejiang Tianhang Biotechnology Co., Ltd. Both rhodamine-conjugated goat anti-mouse antibody (cat. no. ZF-0316) and rhodamine-conjugated goat anti-rabbit antibody (cat. no. ZF-0313) were provided with Beijing Zhongshan Jinqiao Biotechnology Co., Ltd. Cytometric bead array (CBA) Flex Set kit and BCA assay kits were provided by BD Biosciences and Thermo Fisher Scientific, Inc., respectively. Mouse ELISA kits for myeloperoxidase (MPO; cat. no. ml002070), thrombin-antithrombin complex (TATc; cat. no. m1001941), tissue factor pathway inhibitor (TFPI; cat. no. m1001878) and plasminogen activator inhibitor-1 (PAI-1; cat. no. m1037410) were purchased from Miblo.

Mice. A total of 30 7-week-old male wild-type Balb/c mice were obtained from Dashuo Animal Laboratory (license no. SCXK-2015-030). The mice were housed in a standard laboratory environment at a constant temperature $\left(20 \pm 2^{\circ} \mathrm{C}\right)$ and humidity $(50 \pm 10 \%)$ with 12 -h/12-h light/dark cycle with free access to food and water for at least 1 week before use in experiments at 8-10 weeks of age (weight, $23.93 \pm 1.880 \mathrm{~g}$ ). The animal studies were conducted following approval of the Ethics Committee of the Institute of Blood Transfusion, Chinese Academy of Medical Science and Peking Union Medical College (approval no. 201934).

Mouse antibody-mediated TRALI model establishment. Mice were weighed and assigned to one of three groups in a blinded manner. Two-hit TRALI models were induced as previously reported (22). For the TRALI and isotype control groups, low-dose LPS $(0.1 \mathrm{mg} / \mathrm{kg})$ was injected intraperitoneally as the first hit, and, after $18 \mathrm{~h}$, either TRALI-inducing antibody clone $34-1-2 \mathrm{~S}(4.5 \mathrm{mg} / \mathrm{kg})$ or the isotype control antibody $(4.5 \mathrm{mg} / \mathrm{kg})$ was injected via the tail vein as the second hit. The third group comprised untreated control mice.

At $2 \mathrm{~h}$ after challenge with the 34-1-2S and isotype control antibody, the mice were anesthetized with $2.5 \%$ Avertin $(15 \mathrm{ml} / \mathrm{kg})$ intraperitoneally. An aliquot of blood $(200 \mu \mathrm{l})$ from inferior vena cava was drawn in a tube containing ETA-K anticoagulant to count platelets with automated device (XT-1800i; Sysmex). The mice were then sacrificed by cervical dislocation and the lungs collected. The survival rate was evaluated by dividing the number of survivors in each group by the total number of ten animals in each group. Lung wet-to-dry (W/D) weight ratio, lung total protein, lung MPO activity, lung cytokines and lung histology were determined to assess the development of TRALI.

Preparation of lung tissue homogenates. At the experimental endpoint, the lungs were harvested. The left lung was cut into pieces that were homogenized in ice-cold phosphate-buffered saline (0.01 M, pH=7.2-7.4) using a semi-automatic tissue homogenizer. Equivalent volumes of lung tissue homogenates were stored at $-80^{\circ} \mathrm{C}$ for further detection.

Determination of lung W/D weight ratio. The upper and middle parts of the right lung were collected to determine the lung W/D ratio. The fresh lung tissue was weighed to obtain the wet weight. After drying in an oven at $65^{\circ} \mathrm{C}$ for $48 \mathrm{~h}$, the lung tissue was weighed again to determine the dry weight. The W/D weight ratio was calculated as net wet weight/dry weight.

Determination of lung total protein. BCA kits, containing standard, Reagent A and Reagent B, were used to detect lung total protein. The working reagent was prepared by mixing 50 parts of BCA Reagent A with 1 parts of BCA Reagent B. A total of $25 \mu \mathrm{l}$ each standard or lung tissue homogenate and $200 \mu \mathrm{l}$ working reagent were pipetted into the wells of a microplate, which was then incubated at $37^{\circ} \mathrm{C}$ for $30 \mathrm{~min}$. When the plate was cooled to room temperature, lung total protein was determined by measuring the optical density at $562 \mathrm{~nm}$ on a microplate reader.

Determination of lung MPO activity. Standard or lung homogenate $(50 \mu \mathrm{l})$ and enzyme conjugate $(100 \mu \mathrm{l})$ was added to the wells of a microplate and the plate was incubated at $37^{\circ} \mathrm{C}$ for 
$60 \mathrm{~min}$. The plate was then washed. Next, substrate A and substrate B were added into the appropriate wells and the plate was incubated for another $15 \mathrm{~min}$. After stop solution was added into the wells, the absorbance at $450 \mathrm{~nm}$ was measured within 15 min using a microtiter plate reader.

Cytokine analysis. The concentrations of TNF- $\alpha$, IL-1 $\beta$ and IL-6 in aliquots of lung tissue homogenates were determined using a CBA Flex Set kit in accordance with the manufacturer's protocol. All measurements were performed using a flow cytometer (FACSCanto II; BD Biosciences). The data were analyzed using FCAP Array 3.0 software (BD Biosciences).

Coagulation, anticoagulation and fibrinolysis assays. To assess coagulation, anticoagulation and fibrinolysis functions, the levels of TATc, TFPI and PAI-1 in lung tissue homogenates, respectively, were determined using commercial ELISA kits in accordance with the manufacturer's protocols.

Detection of coagulation factor activity and fibrin degradation product $(F D P)$. Lung tissue homogenates were analyzed for coagulation factor activity and FDP using a CA-1500 automated system (Sysmex) in accordance with the manufacturer's instructions. Reagents for coagulation factor activity and FDP detection were obtained from Siemens AG and were prepared accordance with the manufacturer's guidelines. To detect the activities of coagulation factor V (FV), FVII, FVIII and FIX, the samples were incubated with factor-deficient human plasma and mixed with prothrombin time (PT) and partial thromboplastin time (aPTT) reagents. Coagulation factor activity was calculated based on PT and aPTT and a calibration curve. FDP levels were measured by immunoturbidimetry.

Histopathology. Right lung lobes were immersed in $4 \%$ formalin at room temperature for at least $24 \mathrm{~h}$. Then, the tissues were dehydrated in alcohol (75\% alcohol for $4 \mathrm{~h}, 85 \%$ alcohol for $2 \mathrm{~h}, 95 \%$ alcohol for $1 \mathrm{~h}, 100 \%$ alcohol for $0.5 \mathrm{~h}$, and $100 \%$ alcohol for $0.5 \mathrm{~h}$ ), decolored (xylene for $10 \mathrm{~min}$, xylene for $10 \mathrm{~min}$ ), and embedded in soft wax for $1 \mathrm{~h}$ and paraffin for $2 \mathrm{~h}$. Sections were cut at $5-\mu \mathrm{m}$ and placed on microscope slides, deparaffinized, hydrated and stained with hematoxylin for $5 \mathrm{~min}$ and eosin for $3 \mathrm{~min}$ at room temperature. The following four pathological variables were graded: Hemorrhage, white blood cell infiltration, thickness of alveolar wall and lung epithelial cell necrosis. Scores of 0, 1, 2 and 3 represented normal, mild, moderate and severe lung injury, respectively. Total scores for all variables were calculated to evaluate the severity of lung injury.

Immunofluorescence. A part of right lung tissues was fixed in $4 \%$ paraformaldehyde, dehydrated, embedded and cut into sections; these procedures were consistent with those described in the histopathology section. The sections were incubated with sodium citrate solution $(0.01 \mathrm{M})$ for antigen retrieval and then with $10 \%$ bovine serum to block antigens for $30 \mathrm{~min}$ at room temperature. The sections were incubated with rabbit polyclonal anti-fibrinogen (dilution 1:50) and CD41a monoclonal antibody (dilution 1:50) at $4^{\circ} \mathrm{C}$ overnight and then with rhodamine-conjugated goat anti-rabbit antibody and rhodamine-conjugated goat anti-mouse antibody for $30 \mathrm{~min}$ at $37^{\circ} \mathrm{C}$. Nuclei were counterstained with 4',6-diamidino-2-phenylindole. Images were acquired using a fluorescence scanning microscope (P250 FLASH microscope; Danjier Electronic Co., Ltd.). Average fluorescent luminosity was determined using Image-Pro Plus 6.0 software (Media Cybernetics, Inc.). The signal intensity in each image was normalized to the area. The average luminosity in each sample was calculated based on the average luminosity in three images.

Statistical analysis. Data were expressed as the mean \pm standard deviation. Statistical analysis was performed with GraphPad Prism 8 software for MacOS (GraphPad Software, Inc.). Statistical comparisons among different treated groups were evaluated by ANOVA with Tukey's multiple-comparison test and Newman-Keuls multiple-comparison test. Data not conformed as continuous variables were assessed by Kruskal-Wallis test followed by Dunn's multiple-comparison test and expressed as median and interquartile range. The Kaplan-Meier method was used for survival rate comparisons. $\mathrm{P}<0.05$ was considered to indicate a statistically significant difference.

\section{Results}

Histological evidence and severity of antibody-mediated TRALI. Following LPS priming and challenge with an anti-MHC class I molecule (34-1-2S), the mice developed TRALI. Lung damage in the mice was assessed by histological examination (Fig. 1A). As shown in Fig. 1A, the lung injury score was significantly higher in TRALI mice compared with the normal control group. However, there were no significance in the lung injury score between TRALI group and isotype control group (Fig. 1A). Additionally, TRALI mice showed severe lung injury, with a $60 \%$ mortality at $2 \mathrm{~h}$, whereas all mice in the control groups survived (Fig. 1B). These results showed that the TRALI mouse model was successfully established.

Inflammatory responses induced by antibody-mediated TRALI. As TRALI occurs, neutrophils accumulated in the lungs serve an important role in triggering inflammatory responses (23). MPO activity was measured to assess inflammation in the lung. Consistent with previous studies $(24,25)$, pulmonary neutrophil infiltration, as evidenced by increased MPO activity, was typically observed in TRALI mice (Fig. 2A).

To investigate inflammatory responses of TRALI, the current study detected the level of inflammatory cytokines in the lungs. Compared with control group, the levels of TNF- $\alpha$ (Fig. 2B), IL-1 $\beta$ (Fig. 2C) and IL-6 (Fig. 2D) were elevated in TRALI mice. These results clearly indicated the presence of pulmonary inflammation.

Antibody-mediated TRALI induces alteration of the alveolar-capillary barrier. Lung injury damages the alveolar-capillary barrier, leading to protein-rich fluid leakage into the alveolus. Changes in the pulmonary W/D ratio and total protein level can indicate an altered alveolar-capillary barrier. The W/D ratio and total protein level were significantly higher in TRALI mice compared with control mice (Fig. 3A and B).

Antibody-mediated TRALI induces pulmonary fibrin deposition in mice. Preclinical and clinical studies have reported that 
A
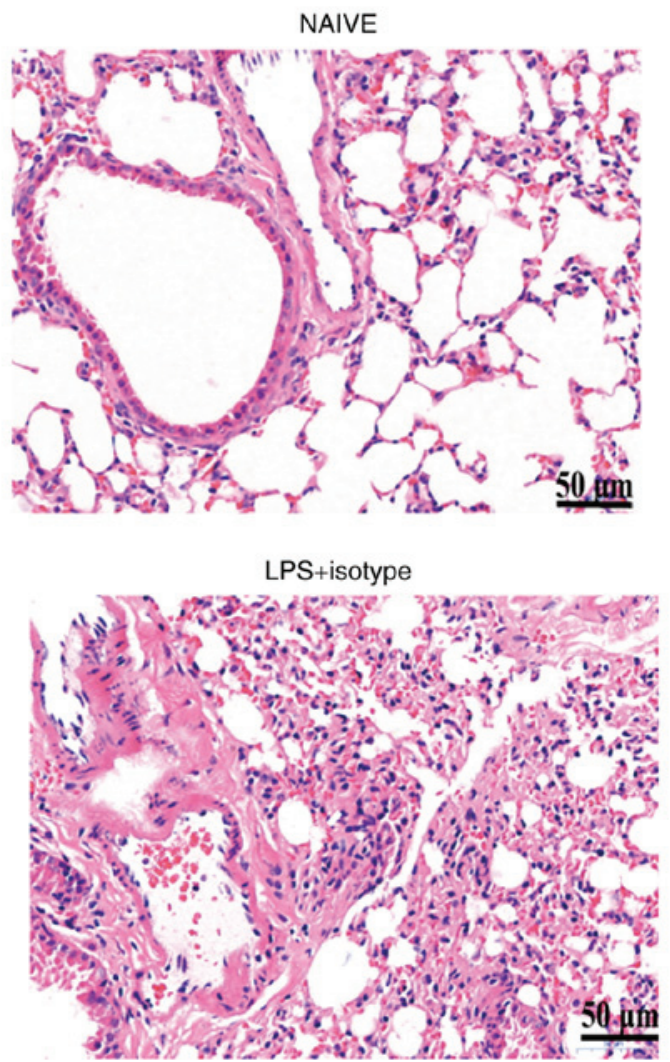

B

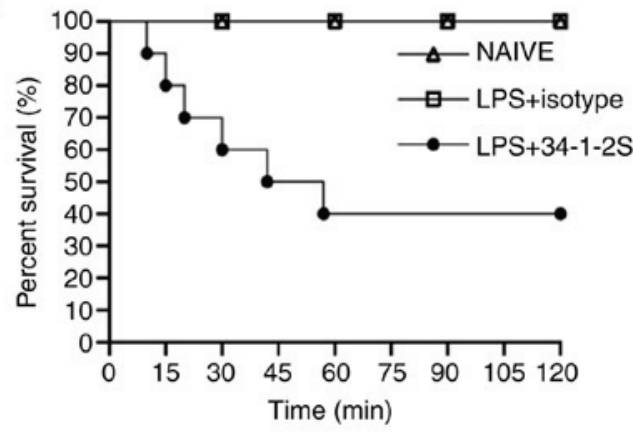

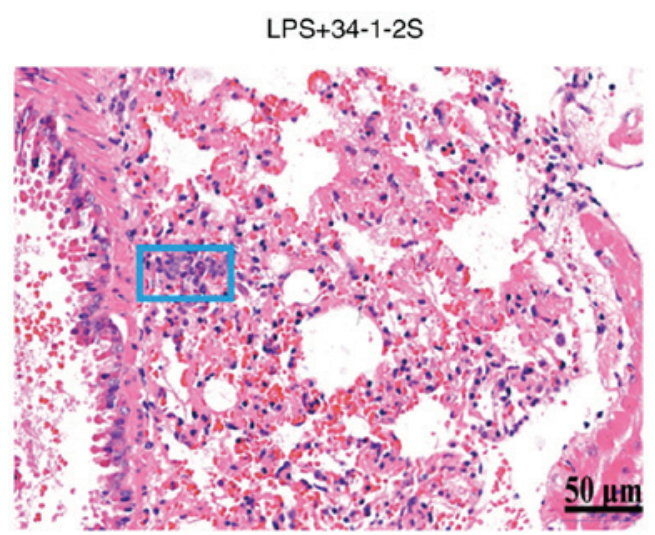

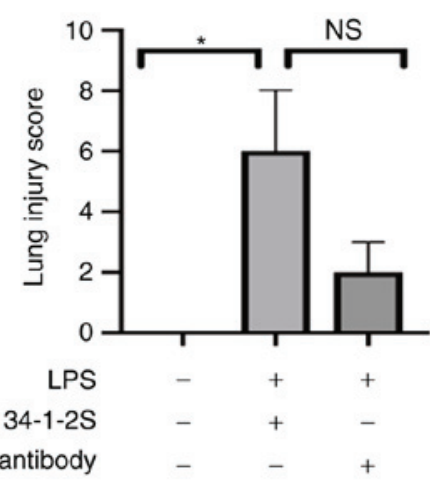

Figure 1. Histological evidence and severity of antibody-mediated TRALI. (A) Hematoxylin and eosin stained lung histology sections photographed (magnification, $\mathrm{x} 400)$ and lung injury scores. Data are presented as the median and interquartile range ( $\mathrm{n}=3$ /group). NS, no significance, $\mathrm{P}<0.05$, by Kruskal-Wallis test followed by Dunn's multiple comparisons test. The most representative of two replicate experiments, which were in good agreement, is shown. The blue rectangle indicates inflammatory cell accumulation. Scale bar, $50 \mu \mathrm{m}$. (B) Kaplan-Meier survival analysis of the treatment groups (n=10 mice/group). TRALI, transfusion-related acute lung injury; LPS, lipopolysaccharide; 34-1-2S, anti-MHC-I molecule.

coagulopathy has a primary role in non-antibody-mediated TRALI $(20,21)$. In addition, pulmonary coagulopathy causes fibrin deposition in the lungs (26). Fibrin can activate endothelial cells, promote inflammatory responses and increase vascular permeability, thus aggravating tissue damage (11). However, no study has focused on pulmonary coagulopathy in antibody-mediated TRALI, to the best of the authors' knowledge. Therefore, fibrin deposition in the lungs was detected by immunofluorescence. The model mice showed strongly enhanced fibrin deposition in the lungs compared with those in the two control groups (Fig. 4).

Whether the enhanced fibrin deposition in antibody-mediated TRALI resulted from enhanced coagulation, inhibited anticoagulation, or impaired fibrinolysis was next determined. Pulmonary TATc was significantly increased in the model mice, indicating the activation of coagulation (Fig. 5A).
Enhanced coagulation may exacerbate pulmonary fibrin deposition (27). Additionally, tissue factor (TF) initiates exogenous coagulation and serves an important role in inflammation and lung injury (28). As a natural inhibitor, TFPI was significantly elevated in the TRALI group compared with that in the normal control group, whereas there was no significant difference with the isotype control group (Fig. 5B). PAI-1 is the main modulator of fibrinolysis. The primary function of PAI-1 is to inhibit plasminogen activator (PA) activity and thus prevent fibrin degradation induced by plasmin. In the present study, the PAI-1 levels in the lungs were significantly higher in the TRALI group than those in the other groups (Fig. 5C).

Increased FV and FVII activities and FVIII and FIX activities, indicate the activation of the extrinsic and intrinsic coagulation pathways, respectively. Therefore, FV, FVII, FVIII and FIX activity was measured using an automated 
A

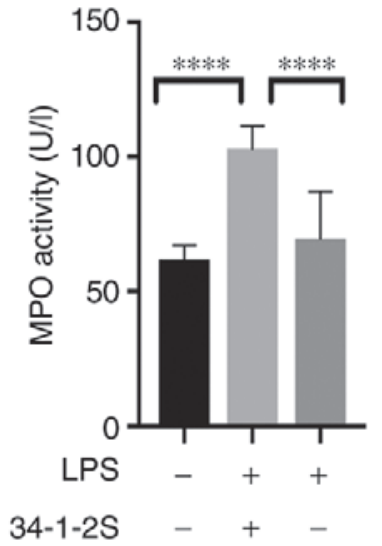

Isotype antibody $\quad-\quad-\quad+$

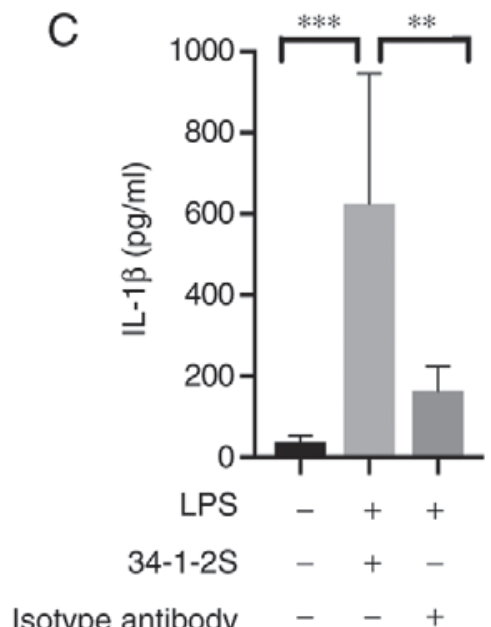

B

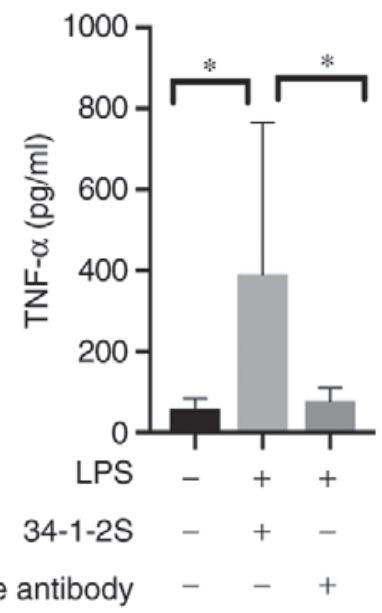

D

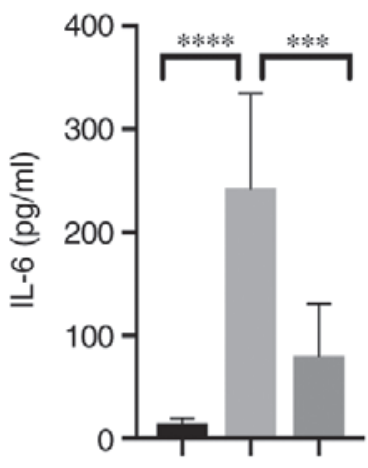

LPS

$34-1-2 S$

Isotype antibody

Figure 2. Inflammatory responses induced by antibody-mediated TRALI in mice. MPO activity (A) and levels of TNF- $\alpha$ (B), IL-1 (C) and IL-6 (D), in the lungs were measured by ELISA. Data are expressed as the mean \pm standard deviation ( $\mathrm{n}=6$ mice/group). ${ }^{*} \mathrm{P}<0.05,{ }^{* * *} \mathrm{P}<0.01,{ }^{* * * *} \mathrm{P}<0.001$ and ${ }^{* * * * *} \mathrm{P}<0.0001$. One-way ANOVA variance of MPO, IL-1 $\beta$ and IL- 6 followed by Tukey's multiple-comparison tests. One-way ANOVA variance of TNF- $\alpha$ followed by Newman-Keuls multiple-comparison tests. MPO, myeloperoxidase; LPS, lipopolysaccharide.

A

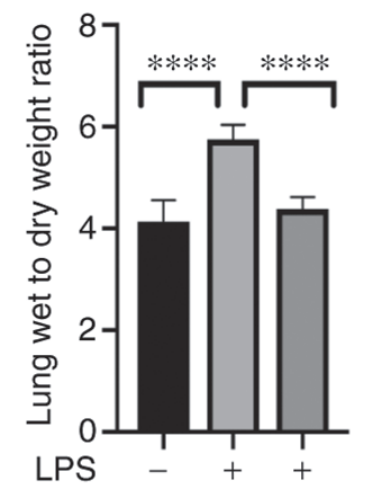

34-1-2S -+-

Isotype antibody $\quad-\quad-\quad+$

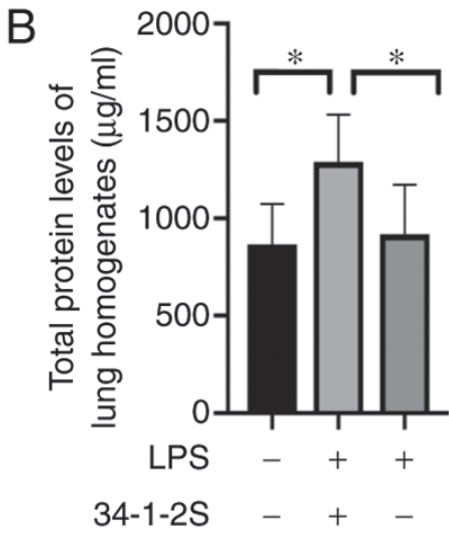

Isotype antibody $\quad-\quad+\quad+$

Figure 3. Antibody-mediated TRALI induces alteration of the alveolar-capillary barrier in mice. (A) Lung wet weight/dry weight ratio ratios in untreated control, isotype control and TRALI mice. (B) Total protein concentrations in lung homogenates. Data are expressed as the mean \pm standard deviation (n=6 mice/group). ${ }^{*} \mathrm{P}<0.05,{ }^{* * * *} \mathrm{P}<0.0001$, by one-way ANOVA followed by Tukey's multiple-comparison test. TRALI, transfusion-related acute lung injury; LPS, lipopolysaccharide.

device. As shown in Fig. 5D, the activity of FV was elevated in TRALI mice compared with that in control mice. However, no differences in FVII, FVIII and FIX activities were observed among the three groups (data not shown). In addition, FDP 
A
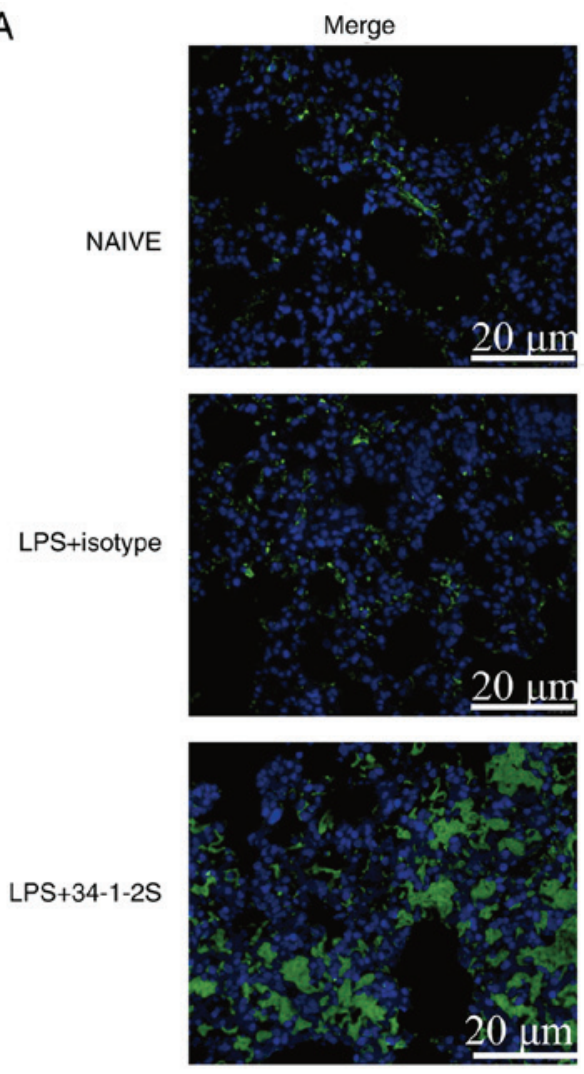
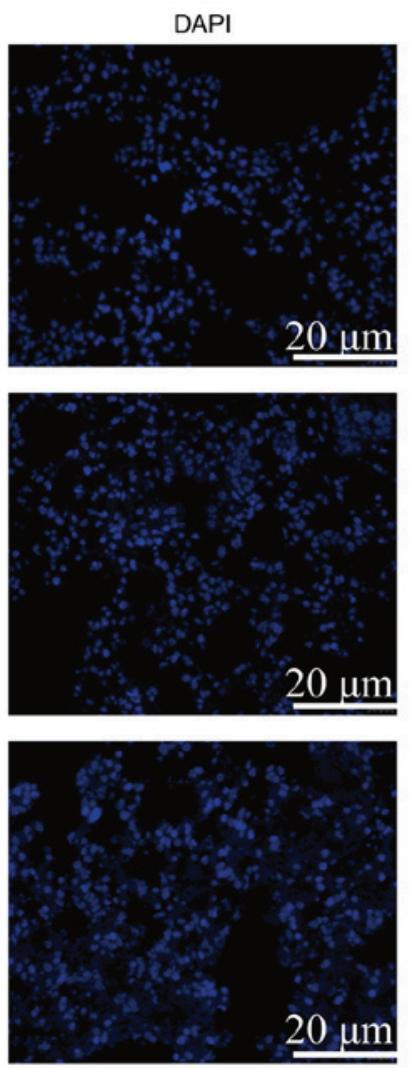

Fibrin
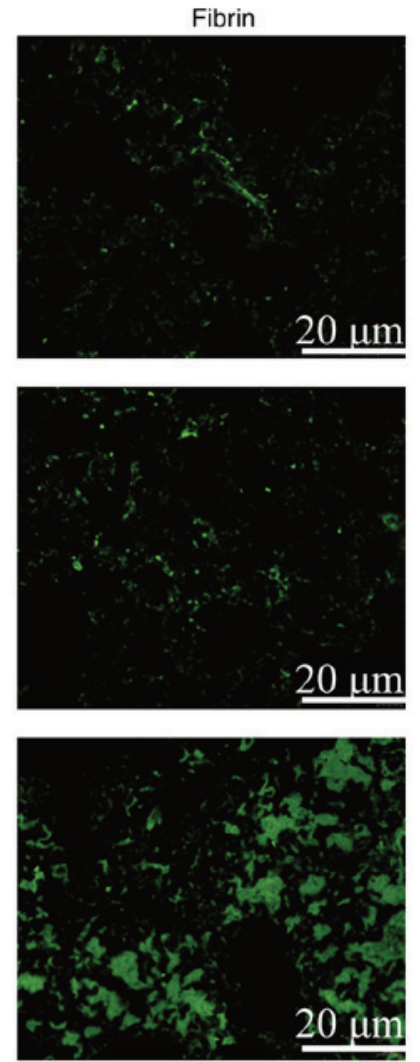

B

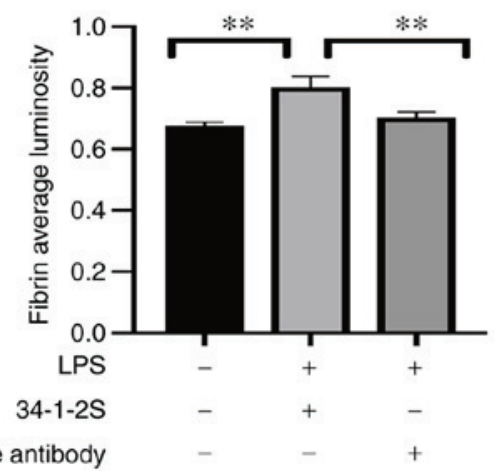

Figure 4. Antibody-mediated TRALI induces pulmonary fibrin deposition in mice. (A) Green, fibrin; blue, DAPI. Scale bar, $20 \mu$ m. Original magnification, $\mathrm{x} 400$. (B) The average fibrin immunofluorescence luminosity was measured using Image-Pro Plus 6.0 software. For each group ( $\mathrm{n}=3$ ), experiments were repeated twice and the most representative results are shown. Data are expressed as the mean \pm standard deviation. ${ }^{* *} \mathrm{P}<0.01$, by one-way ANOVA followed by Tukey's multiple-comparison test. TRALI, transfusion-related acute lung injury.

levels were measured and were markedly decreased in the lungs of TRALI mice compared with those in control mice (Fig. 5E). These results demonstrated that pulmonary fibrinolysis was impaired in antibody-mediated TRALI mice.

Antibody-mediated TRALI induces thrombocytopenia and pulmonary platelet accumulation. Thrombocytopenia is a clinical manifestation of TRALI $(29,30)$. As with a previous study (2), mild thrombocytopenia was observed in the model mice (Fig. 6A). Additionally, platelets are capable to trigger coagulation (31). Thus, platelet accumulation in the lungs was investigated by quantitative immunofluorescence analysis of the platelet-specific marker CD41a. Although platelet staining was observed in the untreated and isotype control mouse lungs, platelet aggregation was enhanced in TRALI mouse lungs (Fig. 6B and C).
Antibody-mediatedTRALI enhances pulmonaryfibrin-platelet interactions. Fibrin, which exerts a proinflammatory effect, drives platelet accumulation in injured lungs, which in turn can amplify the injury (32). In addition, platelets bind fibrin, thus promoting thrombin generation (33). Therefore, the fibrin-platelet interactions in the lungs was measured via immunofluorescence. The results showed that these interactions were increased in antibody-mediated TRALI mice compared with those in control mice (Fig. 7).

\section{Discussion}

An antibody-mediated TRALI mouse model was successfully established by challenging the animals with LPS plus an anti-MHC-I antibody. Preexisting clinical risk factors that confer an inflammatory state appear to mediate a first hit (34). In TRALI 
A

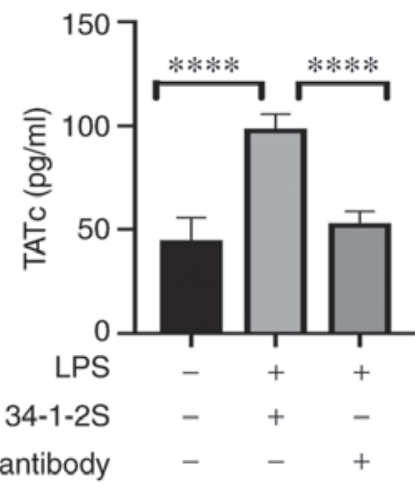

B

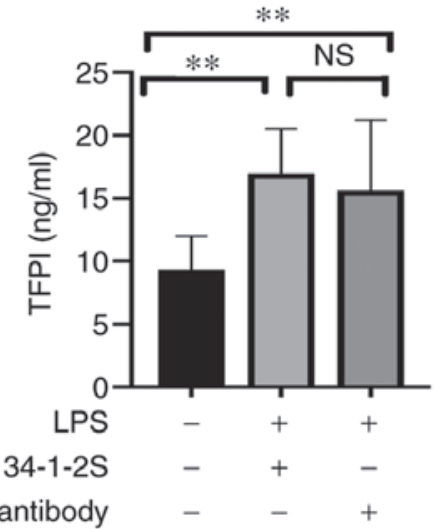

C

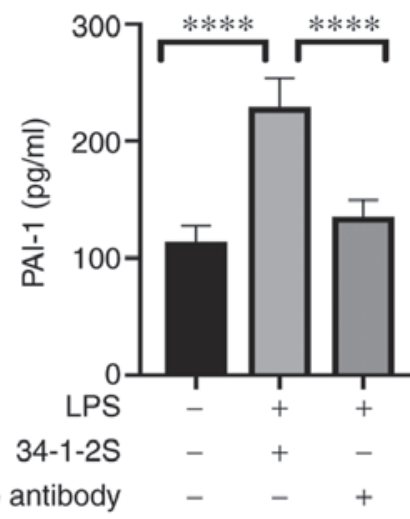

D

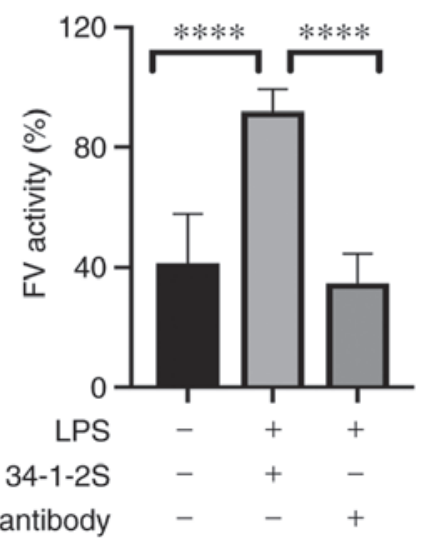

E

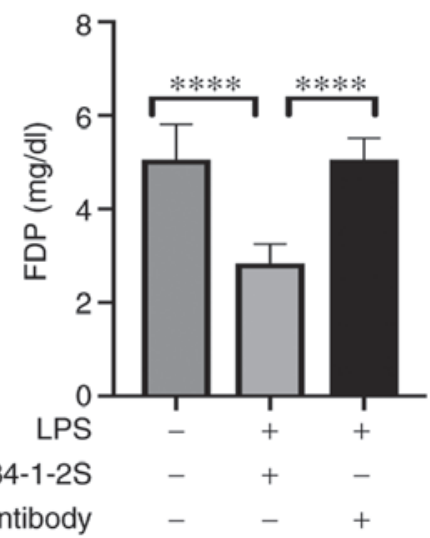

Figure 5. Levels of TATc, TFPI, PAI-1, FV activity and FDP in lung homogenates of the three treatment groups. Levels of (A) TATc, (B) TFPI, (C) PAI-1, and (E) FDP as well as (D) FV activity in lung homogenates. Data are shown as the mean \pm standard deviation (n=5-9 mice/group). ${ }^{* *} \mathrm{P}<0.01,{ }^{* * * *} \mathrm{P}<0.0001$ and $\mathrm{NS}$ = no significance, by one-way ANOVA followed by Tukey's multiple-comparison test. TATc, thrombin-antithrombin complex; TFPI, tissue factor pathway inhibitor; PAI-1, plasminogen activator inhibitor-1; FV, factor V; FDP, fibrin degradation product.

patients, the proportions of antibodies against human leukocyte antigen and human neutrophil antigen are $\sim 50$ and $30 \%$, respectively and these antibodies serve as the second hit (35-37). Overall, the two-hit mechanism underlying disease pathology in the antibody-mediated TRALI mouse model is similar to the pathogenesis of TRALI in patients and thus, the model is representative of human disease. Antibody-mediated TRALI is the major phenotype of clinical TRALI; it accounts for $\sim 80 \%$ of TRALI cases. In the present study, the main characteristics of ALI were confirmed by histological evidence, inflammatory responses and alterations to the alveolar-capillary barrier. Significant fibrin accumulation was observed in TRALI lungs, which was associated with enhanced coagulation and impaired fibrinolysis. Furthermore, platelet sequestration was observed in the TRALI lungs, which might have been caused by fibrin capturing platelets. Additionally, the enhanced coagulation could be related to the binding of platelets to the polymerized fibrin, pulmonary platelet accumulation and enhanced FV activity. Indeed, both increased PAI-1 and decreased FDP in the lungs of the TRALI group indicated that fibrinolysis was inhibited.

Fibrin accumulation in the lungs can induce inflammatory injury, create a proinflammatory environment, reduce gas exchange and aggravate hypoxemia $(9,38,39)$. Corticosteroids ameliorate smoke inhalation-induced ALI by attenuating fibrin deposition (40). Furthermore, PAI-1 deficiency markedly suppresses pulmonary fibrin accumulation and ameliorates alcohol-enhanced ALI (9). Chen et al (41) showed that inhaled NO mitigates endotoxin-induced ALI by suppressing elevated PAI-1 and fibrin deposition. Khalaj et al (16) reported that extracellular vesicle-based therapies can alleviate severe pulmonary conditions by reducing fibrin production. Thus, reduced fibrin deposition in the lungs seems to hold therapeutic potential for lung injury. However, the therapeutic effects of fibrin-lowering drugs in TRALI remain to be elucidated.

In addition to enhanced inflammatory injury, fibrin provides a chemotactic substrate for blood cells, including platelets and leukocytes (42). Platelet integrin $\alpha \operatorname{IIb} \beta 3$ is considered an important functional receptor for fibrin (33). In addition, fibrin-platelet interactions serve a pathogenic role in lung injury. Activated platelets trigger the secretion of adenosine 59-diphosphate and thromboxane A2, which activate integrin $\alpha \mathrm{IIb} \beta 3$ on platelets, facilitating their binding to fibrin and expanding the thrombus (33). $\beta 3$ deficiency impairs the capacity of platelets to bind fibrin, thus preventing alcohol-induced ALI (9). Smyth et al (43) demonstrated that in a model of microvascular thrombosis, $\beta 3$-null mice exhibited less fibrin and thrombi in the lungs than wild-type mice. These results indicated that integrin $\alpha \operatorname{IIb} \beta 3$ on platelets is pivotal for fibrin binding and serves a pathogenic role. Indeed, the present study observed enhanced platelet binding to fibrin in the antibody-mediated TRALI model. However, no evident thrombosis was observed in the model (data not shown). Of 

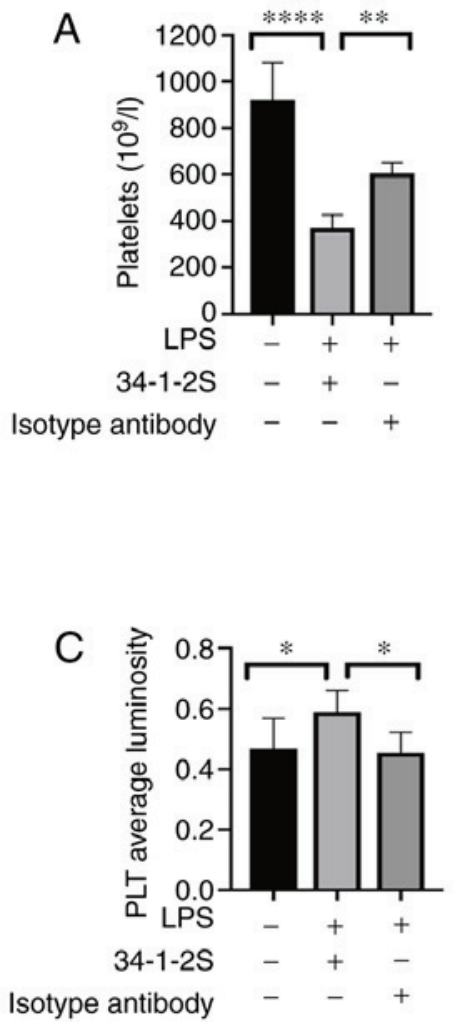

B
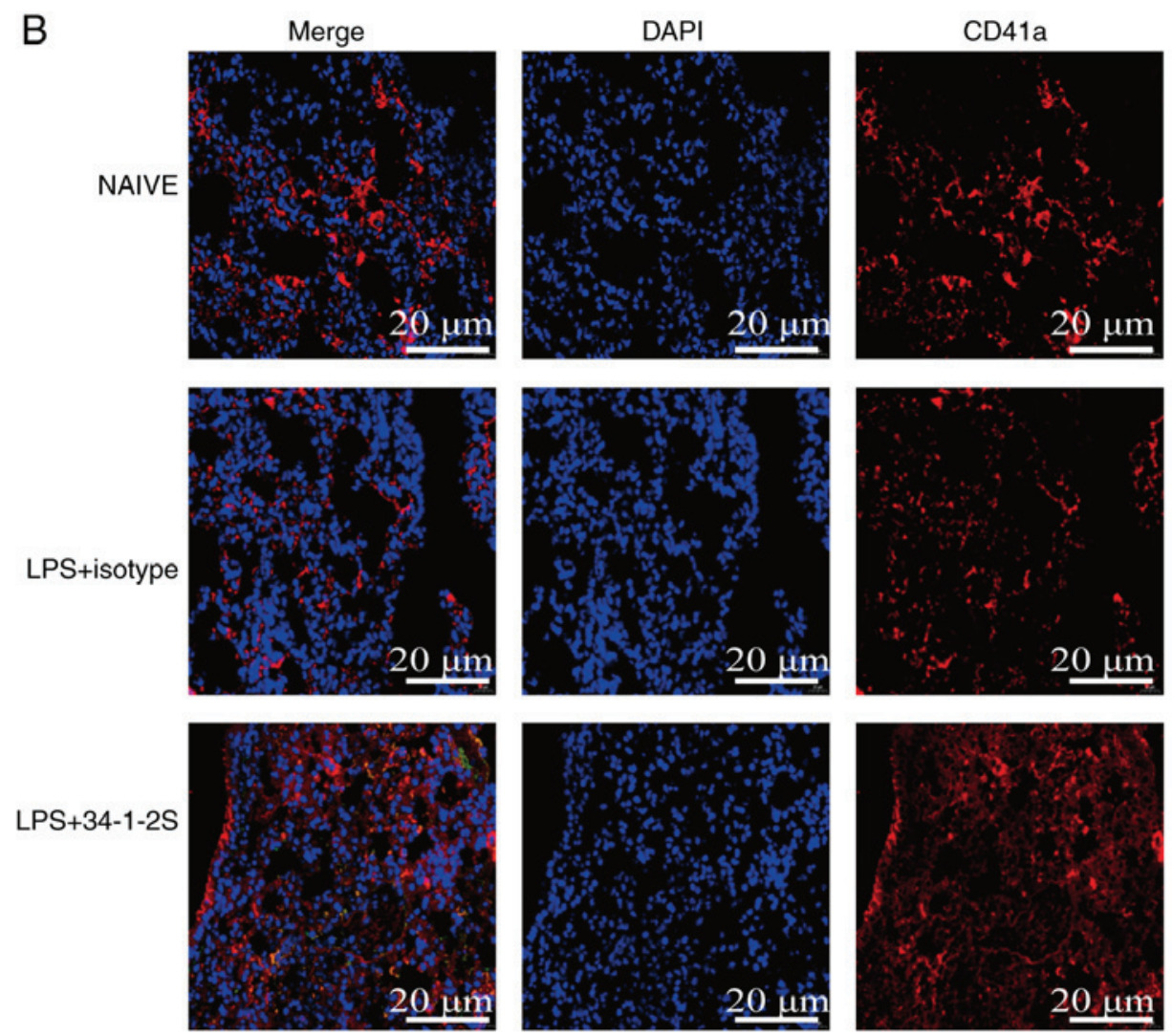

Figure 6. Antibody-mediated TRALI reduces platelets in the peripheral blood and platelets accumulation in the lungs. (A) Numbers of peripheral blood platelets in untreated control, isotype control and TRALI mice. (B) Representative immunostaining for CD41a in untreated, isotype control and TRALI mice. Red, CD41a; blue, DAPI. Scale bar, $20 \mu \mathrm{m}$; original magnification, $\mathrm{x} 400$. (C) The average CD41a immunofluorescence luminosity was determined using Image-Pro Plus 6.0 software. A total of six replicates were included in each group and the most representative images are shown. Data are shown as the mean \pm standard deviation ( $\mathrm{n}=6$ mice/group). ${ }^{*} \mathrm{P}<0.05,{ }^{* *} \mathrm{P}<0.01,{ }^{* * * * *} \mathrm{P}<0.0001$. One-way ANOVA variance of peripheral blood platelets and pulmonary platelets followed by Tukey's multiple-comparison test and Newman-Keuls multiple-comparison test, respectively. TRALI, transfusion-related acute lung injury; PLT, platelet.

note, fibrin-platelet binding promotes platelet aggregation (9). Upon endothelial injury, platelets can be recruited, activated and aggregated via integrin $\alpha \operatorname{IIb} \beta 3$ binding to fibrin (44). Then, platelets that adhere to the lung endothelium exacerbate lung injury by releasing potent proinflammatory molecules and mediators that increase the expression of chemokines and vascular adhesion molecules in endothelial cells $(9,44)$. Pulmonary platelet activation and aggregation reportedly serve pathogenic roles in influenza A-induced pneumonia (44), acid-induced ALI (45), endotoxemia (46) and TRALI (2) and inhibition of platelet function protects against these diseases. Looney et al (2) demonstrated that platelet sequestration following 34-1-2S challenge was associated with the sequestration of platelet-capturing neutrophils in the lungs. Adhesive interactions between neutrophils and platelets are mediated by platelet glycoprotein Ib $\alpha$ and P-selectin binding of glycoprotein ligand-1 and multifunctional leukocyte integrin expressed on leukocytes, respectively (47). Of note, the present study observed increased fibrin deposition in the lungs of TRALI model mice, which could capture platelets and result in platelet sequestration in the lungs. Thrombocytopenia is a common symptom of ARDS and is associated with poor prognosis $(48,49)$. Preclinical models and clinical observations have both shown that thrombocytopenia is a pathogenic manifestation of TRALI (2). In line with previous studies, the present study overserved peripheral blood thrombocytopenia in antibody-mediated TRALI mice. Looney et al (2) demonstrated that thrombocytopenia was related to dynamic neutrophil changes in mouse antibody-mediated TRALI model. It would be worthwhile to investigate whether the decrease in platelets in the systemic circulation of antibody-mediated TRALI is associated with pulmonary fibrin deposition.

Coagulation imbalance commonly occurs in pulmonary disorders and is often accompanied with hypercoagulable conditions, even resulting in pulmonary embolism (12). The present study observed enhanced fibrin deposition in TRALI mice and detected the levels of TATc, TFPI and PAI-1 in the lungs, which are indicators of coagulation, anticoagulation and fibrinolysis, respectively. A hypercoagulable state, enhanced anticoagulation and impaired fibrinolysis was detected in the TRALI group. TATc is an important marker of thrombin and its increased levels indicate a hypercoagulable state. Mammadova-Bach et al (33) reported that the binding of platelet glycoprotein VI (GPVI) to fibrin promotes thrombin generation. In the current study, increased fibrin-platelet binding might have elevated the levels of TATc to some degree, resulting in the hypercoagulable state in TRALI mice. In addition to GPVI, integrin $\alpha \operatorname{IIb} \beta 3$ also mediates fibrin-platelet interaction (33). Whether integrin $\alpha \operatorname{IIb} \beta 3$ mediating fibrin-platelet interaction and triggering thrombin generation in TRALI mice need further validation is for future research. The increased extrinsic coagulation FV activity also 
A
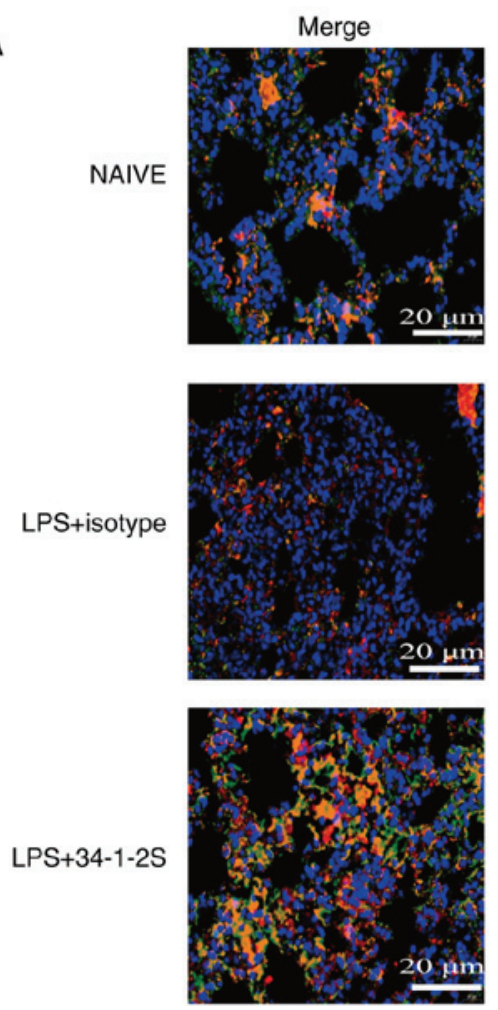
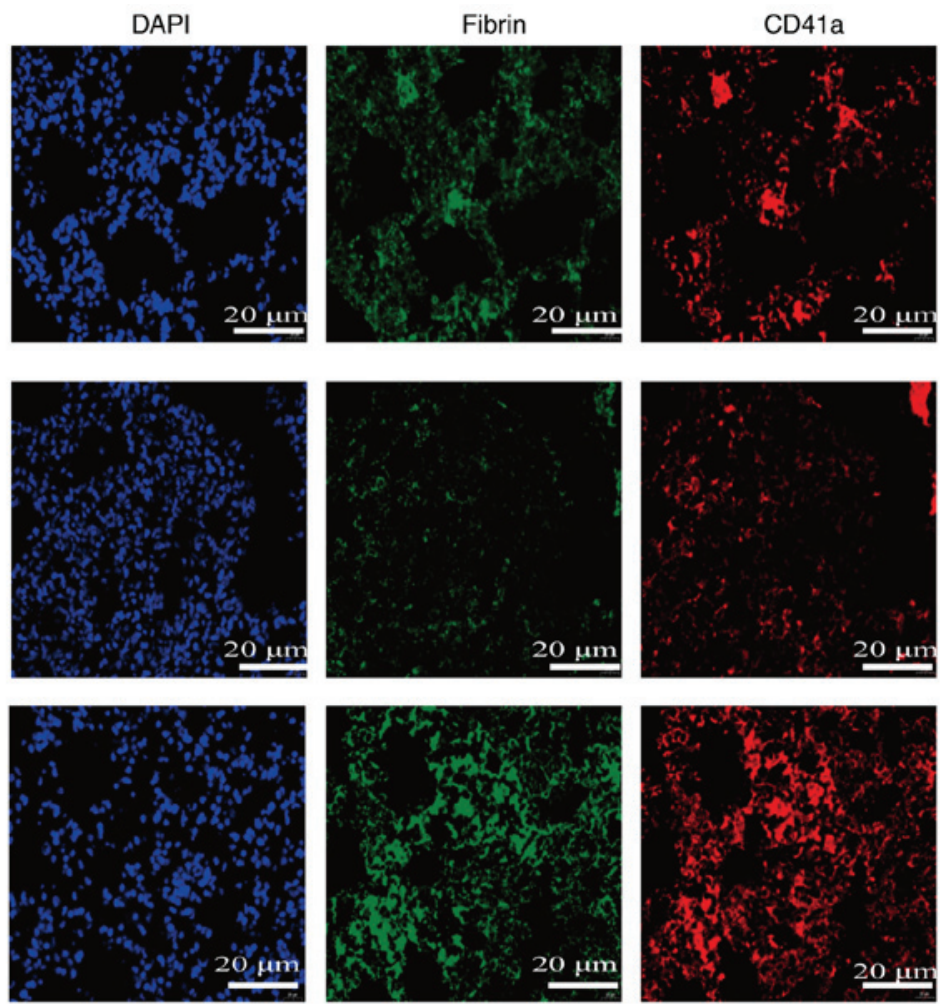

B

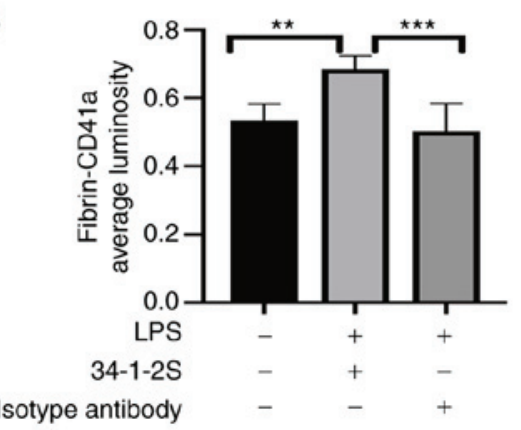

Figure 7. Antibody-mediated TRALI enhances fibrin-platelet interactions in mice. (A) Immunofluorescence staining for CD41a and fibrin in lung tissues of the three treatment groups. Red, CD41a; blue, DAPI; green, fibrin, merged immunofluorescence signals are shown in the leftmost panels. Scale bar, $20 \mu \mathrm{m}$; original magnification, $x 400$. (B) The average fluorescence luminosity was determined using Image-Pro Plus 6.0 software. A total of six replicates were included in each group and the most representative images are shown. Data are shown as the mean \pm standard deviation. $\mathrm{n}=6 \mathrm{mice} / \mathrm{group}$. ${ }^{* *} \mathrm{P}<0.01$, ${ }^{* * *} \mathrm{P}<0.001$, by one-way ANOVA followed by Tukey's multiple-comparison test. TRALI, transfusion-related acute lung injury.

indicated an increase in pulmonary procoagulant activity. Activated platelets offer a procoagulant surface to coagulation factors, resulting in thrombin production (50). In the present study, pulmonary platelet accumulation could have promoted pulmonary thrombin generation by providing a procoagulant surface in TRALI mice. Lung tissue is rich in TF and FVII (51). TFPI inhibits thrombin production and activation by inactivating TF-VII and TF-X conjugate activity (52). Of note, TFPI was increased in the antibody-mediated TRALI group compared with the untreated control group, but not the isotype control group. This result implied that anticoagulation activity increases in the presence of a first hit. Elevated TFPI might diminish FVII and FX procoagulant activities, which could explain why no changes in these activities were observed (data not shown). Although TFPI was able to inhibit thrombin production and activation, the elevated TATc levels indicated that the increase in TFPI was insufficient to control coagulation. PAI-1 facilitates the stable clot formation following injury and participates in posttraumatic coagulopathy (53). FDP originates from fibrin degradation and elevated levels are a manifestation of fibrinolysis (54). In the present study, increased levels of PAI- 1 combined with decreased FDP in the lungs following 34-1-2S challenge indicated the inhibition of fibrinolysis. In addition to PAI-1, fibrinolytic system also includes urokinase-type PA, tissue-type PA, plasminogen and plasmin. Continuing experiments are investigating the expression levels of aforementioned fibrinolytic system components and explain fibrinolysis disorder in detail. In non-antibody-mediated TRALI, the PAI-1 level in bronchoalveolar lavage fluid was elevated, whereas the FDP level was not significantly altered (20). This discrepancy could be explained by differences in the animal species and disease type. In a model of aged erythrocyte transfusion-mediated non-antibody TRALI, increased coagulation and decreased fibrinolysis are observed (20). However, coagulopathy might be induced by aged erythrocytes, which exhibit procoagulant 
activity by enhancing thrombin generation. The present study extended previous findings by confirming, for the first time to the best of the authors' knowledge, that increased coagulation and anticoagulation, as well as impaired fibrinolysis, would enhance fibrin deposition in the lungs and result in platelet accumulation in antibody-mediated TRALI.

Antibody-mediated TRALI is the primary clinical phenotype of TRALI. The findings of enhanced coagulation, increased anticoagulation and impaired fibrinolysis expand and deepen our knowledge of TRALI. However, further research on the complex mechanism of the coagulation-anticoagulation-fibrinolytic system with respect to TRALI are needed. The present study determined the levels of TATc, TFPI, PAI-1, FDP and coagulation factor activity in the lungs instead of in plasma following antibody-mediated TRALI establishment. Nevertheless, assessing these factors in the lungs reveals the pathogenesis in the lungs and is more reliable than assessing systemic levels. The present study discovered that a local coagulation-fibrinolysis imbalance was associated with pulmonary fibrin deposition in antibody-mediated TRALI. The data provide a therapeutic rationale and indicate the feasibility of strategies based on modulating abnormalities in either the coagulation or the fibrinolysis pathway for antibody-mediated TRALI.

\section{Acknowledgements}

Not applicable.

\section{Funding}

The present study was funded by the National Natural Science Foundation of China (grant no.31801192) and CAMS Innovation Fund for Medical Sciences (grant no. 2016-12M-3-024).

\section{Availability of data and materials}

The datasets used and analyzed during the current study are available from the corresponding author on reasonable request.

\section{Authors' contributions}

YY designed the study. YY, PJ, PS and NS performed the experiments. FL collected, analyzed and interpreted the data. YY drafted the manuscript and prepared the figures. PJ edited the manuscript and the figures. FL edited the manuscript and provided financial resources. YY, PJ and FL confirmed the authenticity of all the raw data. All authors reviewed and approved the final manuscript.

\section{Ethics approval and consent to participate}

The animal studies were conducted following the Ethics Committee approval of the Institute of Blood Transfusion, Chinese Academy of Medical Science and Peking Union Medical College (approval no. 201934).

\section{Patient consent for publication}

Not applicable.

\section{Competing interests}

The authors declare that they have no competing interests.

\section{References}

1. Semple JW, Rebetz J and Kapur R: Transfusion-associated circulatory overload and transfusion-related acute lung injury. Blood 133: 1840-1853, 2019.

2. Looney MR, Nguyen JX, Hu Y, Van Ziffle JA, Lowell CA and Matthay MA: Platelet depletion and aspirin treatment protect mice in a two-event model of transfusion-related acute lung injury. J Clin Invest 119: 3450-3461, 2009.

3. Hu A, Chen W, Wu S, Pan B, Zhu A, Yu X and Huang Y: An animal model of transfusion-related acute lung injury and the role of soluble CD40 ligand. Vox Sang 115: 303-313, 2020.

4. Wang L, Wu T, Yan S, Wang Y, An J, Wu C, Zhang Y, Ma Y, Fu Q, Wang D, et al: M1-polarized alveolar macrophages are crucial in a mouse model of transfusion-related acute lung injury. Transfusion 60: 303-316, 2020.

5. Sebag SC, Bastarache JA and Ware LB: Therapeutic modulation of coagulation and fibrinolysis in acute lung injury and the acute respiratory distress syndrome. Curr Pharm Biotechnol 12: 1481-1496, 2011.

6. Ware LB and Matthay MA: The acute respiratory distress syndrome. N Engl J Med 342: 1334-1349, 2000.

7. De Michele S, Sun Y, Yilmaz MM, Katsyv I, Salvatore M Dzierba AL, Marboe CC, Brodie D, Patel NM, Garcia CK, et al: Forty Postmortem Examinations in COVID-19 Patients. Am J Clin Pathol 154: 748-760, 2020.

8. Johnson S, Shaikh SB, Muneesa F, Rashmi B and Bhandary YP: Radiation induced apoptosis and pulmonary fibrosis: Curcumin an effective intervention? Int J Radiat Biol 96: 709-717, 2020.

9. Poole LG, Massey VL, Siow DL, Torres-Gonzáles E, Warner NL, Luyendyk JP, Ritzenthaler JD, Roman J and Arteel GE: Plasminogen activator inhibitor-1 is critical in alcohol-enhanced acute lung injury in mice. Am J Respir Cell Mol Biol 57: 315-323, 2017.

10. Yasui H, Donahue DL, Walsh M, Castellino FJ and Ploplis VA: Early coagulation events induce acute lung injury in a rat model of blunt traumatic brain injury. Am J Physiol Lung Cell Mol Physiol 311: L74-L86, 2016.

11. Vadász I, Morty RE, Olschewski A, Königshoff M, Kohstall MG, Ghofrani HA, Grimminger F and Seeger W: Thrombin impairs alveolar fluid clearance by promoting endocytosis of $\mathrm{Na}^{+}, \mathrm{K}^{+}$-ATPase. Am J Respir Cell Mol Biol 33: 343-354, 2005.

12. Mitchell WB: Thromboinflammation in COVID-19 acute lung injury. Paediatr Respir Rev 35: 20-24, 2020.

13. Tuinman PR, Schultz MJ and Juffermans NP: Coagulopathy as a therapeutic target for TRALI: Rationale and possible sites of action. Curr Pharm Des 18: 3267-3272, 2012.

14. Idell S, James KK, Levin EG, Schwartz BS, Manchanda N, Maunder RJ, Martin TR, McLarty J and Fair DS: Local abnormalities in coagulation and fibrinolytic pathways predispose to alveolar fibrin deposition in the adult respiratory distress syndrome. J Clin Invest 84: 695-705, 1989.

15. Tian LQ, Guo ZH, Meng WZ, Li L, Zhang Y, Yin XH, Lai F, Li Y Y, Feng LL, Shen FF, et al: The abnormalities of coagulation and fibrinolysis in acute lung injury caused by gas explosion. Kaohsiung J Med Sci 36: 929-936, 2020.

16. Khalaj K, Figueira RL, Antounians L, Lauriti G and Zani A: Systematic review of extracellular vesicle-based treatments for lung injury: Are EVs a potential therapy for COVID-19? J Extracell Vesicles 9: 1795365, 2020.

17. Lan CC, Peng CK, Huang SF, Huang KL and Wu CP: Activated protein $\mathrm{C}$ attenuates ischemia-reperfusion-induced acute lung injury. Exp Lung Res 41: 241-250, 2015.

18. Lin L, Lu L, Cao W and Li T: Hypothesis for potential pathogenesis of SARS-CoV-2 infection - a review of immune changes in patients with viral pneumonia. Emerg Microbes Infect 9: 727-732, 2020.

19. Liu C, Ma Y, Su Z, Zhao R, Zhao X, Nie HG, Xu P, Zhu L, Zhang M, Li X, et al: Meta-Analysis of Preclinical Studies of Fibrinolytic Therapy for Acute Lung Injury. Front Immunol 9: 1898, 2018

20. Vlaar AP, Hofstra JJ, Levi M, Kulik W, Nieuwland R, Tool AT, Schultz MJ, de Korte D and Juffermans NP: Supernatant of aged erythrocytes causes lung inflammation and coagulopathy in a 'two-hit' in vivo syngeneic transfusion model. Anesthesiology 113: 92-103, 2010 
21. Tuinman PR, Vlaar AP, Cornet AD, Hofstra JJ, Levi M Meijers JC, Beishuizen A, Schultz MJ, Groeneveld AJ and Juffermans NP: Blood transfusion during cardiac surgery is associated with inflammation and coagulation in the lung: A case control study. Crit Care 15: R59, 2011.

22. Kapur R, Kasetty G, Rebetz J, Egesten A and Semple JW: Osteopontin mediates murine transfusion-related acute lung injury via stimulation of pulmonary neutrophil accumulation. Blood 134: 74-84, 2019

23. Khoy K, Nguyen MVC, Masson D, Bardy B, Drouet C and Paclet MH: Transfusion-related acute lung injury: Critical neutrophil activation by anti-HLA-A2 antibodies for endothelial permeability. Transfusion 57: 1699-1708, 2017.

24. Qiao J, He R, Yin Y, Tian L, Li L, Lian Z, Fang P and Liu Z: rIL-35 prevents murine transfusion-related acute lung injury by inhibiting the activation of endothelial cells. Transfusion 60 : 1434-1442, 2020.

25. He R, Li L, Kong Y, Tian L, Tian X, Fang P, Bian M and Liu Z: Preventing murine transfusion-related acute lung injury by expansion of $\mathrm{CD}^{+}{ }^{+} \mathrm{CD} 25^{+} \mathrm{FoxP}^{+}$Tregs using IL-2/anti-IL-2 complexes. Transfusion 59: 534-544, 2019.

26. Glas GJ, Van Der Sluijs KF, Schultz MJ, Hofstra JJ, Van Der Poll T and Levi M: Bronchoalveolar hemostasis in lung injury and acute respiratory distress syndrome. J Thromb Haemost 11: 17-25, 2013.

27. Chaudhry R, Usama SM and Babiker HM: Physiology, Coagulation Pathways. In: StatPearls StatPearls Publishing Copyright ${ }^{\mathfrak{O}} 2021$. StatPearls Publishing LLC, Treasure Island, FL, 2021.

28. van der Poll T: Tissue factor as an initiator of coagulation and inflammation in the lung. Crit Care 12 (Suppl 6): S3, 2008.

29. Yomtovian R, Kline W, Press C, Clay M, Engman H, Hammerschmidt D and McCullough J: Severe pulmonary hypersensitivity associated with passive transfusion of a neutrophil-specific antibody. Lancet 1: 244-246, 1984.

30. Leger R, Palm S, Wulf H, Vosberg A and Neppert J: Transfusion-related lung injury with leukopenic reaction caused by fresh frozen plasma containing anti-NB1. Anesthesiology 91 $1529-1532,1999$.

31. Li J, Tong D, Chen F, Song B, Wang Y, Liu Y, Zhang X, Liu N $\mathrm{Xu}$ Y, Li Y, et al: Inflammatory cytokines enhance procoagulant activity of platelets and endothelial cells through phosphatidylserine exposure in patients with essential hypertension. J Thromb Thrombolysis 51: 933-940, 2021.

32. Zarbock A and Ley K: The role of platelets in acute lung injury (ALI). Front Biosci 14: 150-158, 2009.

33. Mammadova-Bach E, Ollivier V, Loyau S, Schaff M, Dumont B, Favier R, Freyburger G, Latger-Cannard V, Nieswandt B, Gachet C, et al: Platelet glycoprotein VI binds to polymerized fibrin and promotes thrombin generation. Blood 126: 683-691, 2015.

34. Kapur R, Kim M, Aslam R, McVey MJ, Tabuchi A, Luo A, Liu J, Li Y, Shanmugabhavananthan S, Speck ER, et al: T regulatory cells and dendritic cells protect against transfusion-related acute lung injury via IL-10. Blood 129: 2557-2569, 2017.

35. Peters AL, Van Stein D and Vlaar AP: Antibody-mediated transfusion-related acute lung injury; from discovery to prevention. $\mathrm{Br}$ J Haematol 170: 597-614, 2015.

36. Kosmaczewska A: Low-dose interleukin-2 therapy: A driver of an imbalance between immune tolerance and autoimmunity. Int J Mol Sci 15: 18574-18592, 2014

37. Bayat B, Tjahjono Y, Sydykov A, Werth S, Hippenstiel S, Weissmann N, Sachs UJ and Santoso S: Anti-human neutrophil antigen-3a induced transfusion-related acute lung injury in mice by direct disturbance of lung endothelial cells. Arterioscler Thromb Vasc Biol 33: 2538-2548, 2013

38. Gallelli L, Zhang L, Wang T and Fu F: Severe acute lung injury related to COVID-19 infection: A review and the possible role for Escin. J Clin Pharmacol 60: 815-825, 2020.
39. Lau CL, Zhao Y, Kim J, Kron IL, Sharma A, Yang Z, Laubach VE, Linden J, Ailawadi G and Pinsky DJ: Enhanced fibrinolysis protects against lung ischemia-reperfusion injury. J Thorac Cardiovasc Surg 137: 1241-1248, 2009.

40. Song LC, Chen XX, Meng JG, Hu M, Huan JB, Wu J, Xiao K, Han ZH and Xie LX: Effects of different corticosteroid doses and durations on smoke inhalation-induced acute lung injury and pulmonary fibrosis in the rat. Int Immunopharmacol 71: 392-403, 2019.

41. Chen Y, Lu ZJ, Yang Y, Lu GP, Chen WM and Zhang LE: Suppression of plasminogen activator inhibitor-1 by inhaled nitric oxide attenuates the adverse effects of hyperoxia in a rat model of acute lung injury. Thromb Res 136: 131-138, 2015.

42. Perez RL and Roman J: Fibrin enhances the expression of IL-1 beta by human peripheral blood mononuclear cells. Implications in pulmonary inflammation. J Immunol 154: 1879-1887, 1995.

43. Smyth SS, Reis ED, Väänänen $H$, Zhang $W$ and Coller BS: Variable protection of beta 3-integrin--deficient mice from thrombosis initiated by different mechanisms. Blood 98: 1055-1062, 2001

44. Lê VB, Schneider JG, Boergeling Y, Berri F, Ducatez M, Guerin JL, Adrian I, Errazuriz-Cerda E, Frasquilho S, Antunes L, et al: Platelet activation and aggregation promote lung inflammation and influenza virus pathogenesis. Am J Respir Crit Care Med 191: 804-819, 2015.

45. Zarbock A, Singbartl K and Ley K: Complete reversal of acid-induced acute lung injury by blocking of platelet-neutrophil aggregation. J Clin Invest 116: 3211-3219, 2006.

46. Kiefmann R, Heckel K, Schenkat S, Dörger M and Goetz AE: Role of p-selectin in platelet sequestration in pulmonary capillaries during endotoxemia. J Vasc Res 43: 473-481, 2006.

47. Simon DI, Chen Z, Xu H, Li CQ, Dong J, McIntire LV, Ballantyne CM, Zhang L, Furman MI, Berndt MC, et al: Platelet glycoprotein ibalpha is a counterreceptor for the leukocyte integrin Mac-1 (CD11b/CD18). J Exp Med 192: 193-204, 2000.

48. Greinacher A and Selleng S: How I evaluate and treat thrombocytopenia in the intensive care unit patient. Blood 128: 3032-3042, 2016

49. Wei Y, Tejera P, Wang Z, Zhang R, Chen F, Su L, Lin X, Bajwa EK, Thompson BT and Christiani DC: A missense genetic variant in LRRC16A/CARMIL1 improves acute respiratory distress syndrome survival by attenuating platelet count decline. Am J Respir Crit Care Med 195: 1353-1361, 2017.

50. Tohidi-Esfahani I, Lee CS, Liang HP and Chen VM: Procoagulant platelets: Laboratory detection and clinical significance. Int J Lab Hematol 42 (Suppl 1): 59-67, 2020.

51. Idell S, Peters J, James KK, Fair DS and Coalson JJ: Local abnormalities of coagulation and fibrinolytic pathways that promote alveolar fibrin deposition in the lungs of baboons with diffuse alveolar damage. J Clin Invest 84: 181-193, 1989.

52. Wood JP, Ellery PE, Maroney SA and Mast AE: Biology of tissue factor pathway inhibitor. Blood 123: 2934-2943, 2014.

53. Griemert EV, Schwarzmaier SM, Hummel R, Gölz C, Yang D, Neuhaus W, Burek M, Förster CY, Petkovic I, Trabold R, et al: Plasminogen activator inhibitor-1 augments damage by impairing fibrinolysis after traumatic brain injury. Ann Neurol 85: 667-680, 2019.

54. Wang L, He WB, Yu XM, Hu DL and Jiang H: Prolonged prothrombin time at admission predicts poor clinical outcome in COVID-19 patients. World J Clin Cases 8: 4370-4379, 2020.

This work is licensed under a Creative Commons Attribution-NonCommercial-NoDerivatives 4.0 International (CC BY-NC-ND 4.0) License. 